\title{
The Impact of Gastroesophageal Reflux on the Quality of Life: About a Series of 100 Patients at Fez University Hospital
}

\author{
Houda Meyiz ${ }^{1,2}$, Mohammed El Agheb ${ }^{1,2}$, Asmae Lamine ${ }^{1,2}$, Mounia El Yousfi ${ }^{1,2}$, Nordin Aqodad ${ }^{1,2}$, \\ Dafr Benajeh", ${ }^{1,2}$ Mohammed El Abkari, ${ }^{1,2}$, Adil Ibrahimi ${ }^{1,2}$, Ihsane Mellouki,
}

\author{
${ }^{1}$ Hepato-Gastroenterology Department, Hassan II University Medical Center, Fez, Morocco \\ ${ }^{2}$ Faculty of Medicine, Sidi Mohammed Ben Abdellah University, Fez, Morocco \\ Email: houdameyiz@hotmail.fr
}

How to cite this paper: Meyiz, H., El-Agheb, M., Lamine, A., El-Yousfi, M., Aqodad, N., Benajeh, D., El-Abkari, M., Ibrahimi, A. and Mellouki, I. (2019) The Impact of Gastroesophageal Reflux on the Quality of Life: About a Series of $100 \mathrm{~Pa}-$ tients at $\mathrm{Fez}$ University Hospital. Open Journal of Gastroenterology, 9, 99-108. https://doi.org/10.4236/ojgas.2019.96012

Received: May 21, 2019

Accepted: June 24, 2019

Published: June 27, 2019

Copyright $\odot 2019$ by author(s) and Scientific Research Publishing Inc. This work is licensed under the Creative Commons Attribution International License (CC BY 4.0).

http://creativecommons.org/licenses/by/4.0/

\begin{abstract}
The gastroesophageal reflux disease (GERD) represents a major problem for public health because of its high prevalence. The chronic character of the symptoms can have a very important impact on the quality of life (QoL). The purpose of this study is to assess the impact of the GERD on the quality of life of our patients and to determine the main aggravating factors. Patients and Methods: This is a cross-sectional, observational study of 100 patients presenting signs of GERD in the gastroenterology department of the university medical center Hassan II-Fez, for a period of 3 months (October to December 2014). We used the Reflux-Qual short form $\left(\mathrm{RQS}^{\circledR}\right)$ to evaluate the QoL of our patients. Results: Over the study period, 100 patients were included. The average age of our patients was 47 years [20 - 75 years] with a sex-ratio F/M in 2.12. Among our patients, $20 \%(\mathrm{n}=20)$ were chronic cigarette smokers. The diagnosis of GERD was clinical in $75 \%$ of the cases $(n=75)$ and based on 24 -hour $\mathrm{pH}$ monitoring in the remaining $25 \%(\mathrm{n}=25)$. Approximately $2 / 3$ of the patients were receiving proton pump inhibitors (PPIs) treatment at the time of the questionnaire. The impairment of QoL was moderated to severe $\left(\mathrm{RQS}^{\circledR}<16\right)$ for $62 \%$ of the patients $(\mathrm{n}=62)$. This impairment was associated with elderly $(p=0.01)$, female sex $(p=0.03)$ and the frequency of symptoms $(p=0.001)$. Moreover, patients having a GERD that requiring a daily and continuous administration of PPIs had a lower index of $\operatorname{RQS}^{\circledR}(p=0.001)$. The quality of life impairment was not associated with chronic cigarette smoking $(p=0.3)$. Conclusion: The impairment of the QoL was moderated to severe $\left(\mathrm{RQS}^{\circledR}<16\right)$ for $2 / 3$ of the patients $(\mathrm{n}=62)$. This impairment was associated with elderly, female sex, frequency and in case of GERD requiring continuous administration of PPIs.
\end{abstract}




\section{Keywords}

Gastroesophageal Reflux, Reflux-Qual Short Form, Quality of Life

\section{Introduction}

The gastroesophageal reflux (GERD) is a common chronic disease. Some epidemiological studies are suggesting a prevalence reaching up to $20 \%-40 \%$ of the adult in the western population, among them $5 \%-10 \%$ present daily heartburn or regurgitation [1]. In Morocco, data on the prevalence of GERD are not available due to the lack of epidemiological studies in the general population.

Correlation between esophageal lesions and symptoms is only imperfect. Esophagitis is noted in endoscopy only in $50 \%-65 \%$ of patients with symptoms [2] [3]. Quality of life is an excellent indicator, widely used in gastroenterology, initially to assess the impact of GERD and secondly to test the effectiveness of the treatments introduced. Therefore, it is essential to assess the impact of these disorders on the quality of life of patients (QoL).

Several questionnaires were proposed to assess this QoL. The Reflux-Qual ${ }^{\circledR}$ is a validated QoL questionnaire specific to GERD including 37 items, but not practical for use in everyday medical practice [4]. Consequently, a short form of the questionnaire the RQS ${ }^{\circledR}$ was developed, including 8 items and covering the principal domains of the patient's QoL [5].

Numerous international studies have been carried out and confirmed the impairment of the quality of life in patients with GERD [6]. In Morocco, We have no data concerning the quality of life of patients with GERD. The purpose of this study is to assess the impact of the GERD on the life quality of Moroccan patients and to determine the main aggravating factors.

\section{Material and Methods}

This is a cross-sectional, observational study of 100 patients presenting signs of GERD in the gastroenterology department of the university medical center Hassan II-Fez, for 3 months (from October to December 2014).

\subsection{Sample Size}

On an estimate of $15 \%$ of consultants per month for GERD, for a study period of 3 months, we assumed that the confidence interval of 5\% and a confidence level of $95 \%$. The sample size obtained for this study was 100 patients.

\subsection{Inclusion Criteria}

Any patient over 15 years old, both sexes, recruited from hepato-gastroenterology consultation, with one or more clinical sign of typical GERD (heartburn, regurgitation), associated or not with atypical signs: (epigastric pain, belching, dysphagia, chronic cough, laryngitis, new or worsening asthma). 


\subsection{Exclusion Criteria}

- Significant impact on overall condition (weight loss, asthenia).

- Exterior digestive hemorrhage.

- Comorbidities (kidney disease, heart disease, diabetes).

- History of esophageal or gastric surgery.

- Known esophageal motor disorders.

- Pregnancy, breastfeeding.

- Participation refusal.

\subsection{Procedure Methodology}

Patients with atypical signs of GERD, or alarm signs, over than 50 years, with failure or recurrence after medical treatment have to undergo upper endoscopy.

After written informed consent was obtained, a well-designed questionnaire was used to collect the data of the recruited patients. The questionnaire included socio-demographic characteristics such as age, gender, nationality, origin, school level, profession, and smoking status, type of symptoms, its duration, frequency, and severity. This questionnaire was administrated by the treating physician.

\subsection{Quality of Life Scale}

We used the Reflux-Qual short form $\left(\mathrm{RQS}^{\circledR}\right)$ which we translated into the Arabic language. This score was filled by the patients themselves. For illiterate patients, the questionnaire has been translated and administered by the same person in dialect Arabic, keeping the same meaning and the same terms. The average time of the questionnaire is estimated at 10 minutes. The Reflux-Qual short form $\left(\mathrm{RQS}^{\circledR}\right)$ consists of 8 items. A score ranging from 0 to 32 , with scores tending to 32 indicating a better quality of life.

\subsection{Statistical Analysis}

Statistical analysis of the data was done using Excel software and Epi Info 2007 for Windows. Initially, a descriptive analysis of the socio-demographic and clinical characteristics as well as a description of the population based on the quality of life and severity of symptoms was performed. Descriptive analysis was performed using proportions calculations for qualitative variables (frequency, percentage), means for quantitative variables. In a second time, we proceeded to univariate analyses of factors associated with quality of life and severity of symptoms. The level $p<0.05$ was considered as the cutoff value or significance.

\section{Results}

During the study period, 100 patients were included among 495 patients admitted to medical consultation. The prevalence of GERD is estimated at $20.2 \%$. The average age of our patients was 47 years old, with extremes ranging from 20 to 75 years old. Patients over 40 years old represent $67 \%$ of the total number of 
cases $(n=67)$. A clear female predominance was noted with a sex-ratio F/M of 2.12. Of our patients, $69 \%$ were from urban origin $(n=69)$, and $35 \%$ of the patients were illiterate $(\mathrm{n}=35)$ (Table 1$)$.

The onset of symptoms was less than 12 months ago in $32 \%$ of cases $(n=32)$, while symptoms had been developing for more than 2 years in $49 \%$ of the cases $(\mathrm{n}=49)$. In addition, $20 \%$ of patients were chronic smokers $(\mathrm{n}=20)$ and $19 \%$ were asthmatics $(n=19)$.

In terms of clinical presentation, $75 \%$ of patients had heartburn associated with regurgitation, epigastric pain in $15 \%$ of cases, chronic cough in $5 \%$, expiratory dyspnea in $4 \%$, and dysphagia in $3 \%$ of cases. Symptoms are considered moderate to severe for $83 \%$ of patients, and nocturnal in $49 \%$ of cases (Table 2). The occurrence rate of symptoms was daily in $24 \%$ of cases, and very common (>3 days/week) in 39\% of cases. Upper endoscopy (EGD) was performed in $20 \%$ of cases $(n=20)$. It was normal in $9 \%$ of cases. Esophageal 24 -hour pH monitoring highlighted pathological GERD in $25 \%$ of cases (Table 2). Fifty-four patients were receiving IPPs-based anti-reflux therapy single dose at the time of the questionnaire.

Moderate to severe quality of life impairment $\left(\mathrm{RQS}^{\circledR}<16\right)$ was noted in $62 \%$ of patients $(n=62)$. This deterioration in the quality of life is more common in subjects older than 40 years old $(p=0.01)$, and female patients $(p=0.03)$. The decrease in this quality of life score was more pronounced when symptoms are more frequent (daily or $>3$ days/week) $(p=0.001)$. Patients with daily GERD symptoms, requiring a continuous intake of PPIs, had a lower RQS ${ }^{\circledast}$ index, testifying a greater deterioration in their quality of life compared to other patients ( $p$ $=0.001)$. On the other hand, there was no statistically significant association between the severity of the quality of life and chronic cigarette smoking $(p=0.3)$ (Table 3).

Table 1. Socio-demographic characteristics of patients with GERD, in the gastroenterology department of the university medical center Hassan II-Fez, from October to December, $\mathrm{n}=100$.

\begin{tabular}{ccc}
\hline $\begin{array}{c}\text { Socio-demographic } \\
\text { characteristics }\end{array}$ & $\mathrm{n}$ & $\%$ \\
\hline Sex-ratio & $2.12(68 \mathrm{~F} / 32 \mathrm{H})$ & \\
Mean age & 47 years $(20-75)$ & \\
Age range: & & $33 \%$ \\
$<40$ years & 33 & $67 \%$ \\
$\geq 40$ years & 67 & \\
Origin: & & $69 \%$ \\
Urban & 69 & $31 \%$ \\
Rural & 31 & $35 \%$ \\
Level of education: & & $55 \%$ \\
Illiterate & 35 & $10 \%$ \\
Primary or secondary school & 55 & \\
High school & 10 & \\
\hline
\end{tabular}


Table 2. Clinical characteristics of patients with GERD, in the gastroenterology department of the university medical center Hassan II-Fez, from October to December 2014, n $=100$.

\begin{tabular}{ccc}
\hline Clinical characteristics & $\mathrm{n}$ & $\%$ \\
\hline The onset of symptoms & 38 & $38 \%$ \\
$\leq 12$ months & 37 & $37 \%$ \\
$>12$ months/ $\leq 60$ months & 10 & $10 \%$ \\
$>60$ months/ $\leq 120$ months & 15 & $15 \%$ \\
$>120$ months & & \\
Symptoms & 75 & $75 \%$ \\
Heartburn + regurgitation & 15 & $15 \%$ \\
Epigastric pain & 5 & $5 \%$ \\
Chronic cough & 4 & $4 \%$ \\
Expiratory dyspnea & 3 & $3 \%$ \\
Dysphagia & & \\
Rhythm & 31 & $31 \%$ \\
Diurnal & 20 & $20 \%$ \\
Nocturnal & 49 & $49 \%$ \\
Mixte & & \\
Frequency & 24 & $24 \%$ \\
Daily & 39 & $39 \%$ \\
$>3$ days/week & 29 & $29 \%$ \\
$>1$ days/week & 8 & $8 \%$ \\
$<3$ days/month & & \\
Upper endoscopy (n $=20)$ & 9 & $25 \%$ \\
Normal & 5 & $5 \%$ \\
Peptic esophagitis & 5 & \\
Hiatal hernia & 1 & \\
Barrett's esophagus & & \\
\hline
\end{tabular}

Table 3. Risk factors of moderate to severe quality of life impairment $\left(\mathrm{RQS}^{\circledR}<16\right)$ of patients with GERD, in the gastroenterology department of the university medical center Hassan II-Fez, from October to December 2014, $\mathrm{n}=100$.

\begin{tabular}{|c|c|c|c|c|c|c|}
\hline \multirow{3}{*}{\multicolumn{2}{|c|}{ Risk factors }} & \multicolumn{4}{|c|}{$\mathrm{RQS}^{\circledR}$} & \multirow{3}{*}{$p$} \\
\hline & & \multicolumn{2}{|c|}{$\begin{array}{c}\geq 16 \\
(\mathrm{n}=38)\end{array}$} & \multicolumn{2}{|c|}{$\begin{array}{c}<16 \\
(\mathrm{n}=62)\end{array}$} & \\
\hline & & $\mathrm{n}$ & $\%$ & $\mathrm{n}$ & $\%$ & \\
\hline \multirow{2}{*}{ Age } & $\geq 40$ years & 18 & 47 & 49 & 79 & \multirow{2}{*}{0.01} \\
\hline & $<40$ years & 20 & 53 & 13 & 21 & \\
\hline \multirow[b]{2}{*}{ Sex } & Female & 21 & 55 & 47 & 76 & \multirow[b]{2}{*}{0.03} \\
\hline & Male & 17 & 45 & 15 & 24 & \\
\hline \multirow{2}{*}{ Frequency } & yes & 15 & 39 & 48 & 77 & \multirow{2}{*}{0.001} \\
\hline & no & 23 & 61 & 14 & 23 & \\
\hline \multirow[b]{2}{*}{ PPIs intake } & yes & 9 & 24 & 45 & 73 & \multirow[b]{2}{*}{0.001} \\
\hline & $\mathrm{no}$ & 20 & 76 & 17 & 27 & \\
\hline \multirow{3}{*}{$\begin{array}{l}\text { Chronic } \\
\text { smoking }\end{array}$} & & & & & 11 & \multirow{3}{*}{0.3} \\
\hline & yes & 9 & 24 & 11 & 18 & \\
\hline & no & 29 & 76 & 51 & 82 & \\
\hline
\end{tabular}




\section{Discussion}

The prevalence of GERD varies widely internationally, within and between countries. Most of these studies are often based on postal questionnaires or telephone interviews inviting individuals to self-assess symptoms, and these responses are then evaluated by investigators according to a set of criteria. The prevalence of GERD in western countries is up to $20 \%-40 \%$ [1]. Our study in the hospital center shows a prevalence of $20.2 \%$. In Morocco, no data are available due to the lack of epidemiological studies in the general population. Our estimation of the prevalence remains higher than the prevalence in China and Japan with a value of $6.7 \%$ and $10.2 \%$ respectively [7] [8]. This frequency is much lower than in France with a prevalence estimated at 31.3\% [9]. The heterogeneity between studies is explained by differences in sampling and methodology.

A clear female predominance was observed in our series with a sex-ratio $\mathrm{F} / \mathrm{M}$ at 2.12, comparable to that noted by the Iranian series of Maleki, where the sex-ratio F/M was 2.23 [10]. This finding is identical to the literature data, that the GERD is more common in women than in men [11]. It is likely to reflect differences in behavior towards illness.

The average age of our patients was 47 years old (20 - 75 years). Patients over 40 years old account for $67 \%$ of cases $(\mathrm{N}=67)$. Our data are comparable to those reported by the Firoozi [12], where the average age was estimated to 49 years old without any difference in average age in both sexes. Patients over 40 years represent also the majority of cases [12]. Indeed, the GERD occurs in all age groups, including children and the elderly.

Our patients with pyrosis and regurgitation represent $75 \%$, joining the literature data, in particular, Ben Hriza series, where it represents $73 \%$ of cases [13]. Epigastric pain is often associated with GERD. In fact, in the Firoozi series [12] it was associated with GERD in $18 \%$ compared to the data in our series.

Although uncomplicated GERD does not involve the vital prognosis, it is a chronic recurrent disease that is often associated with alteration of the quality of life. Several studies carried out in recent years have shown a significant alteration of QoL in patients with GERD compared to the healthy population [14] [15]. Our study showed that patients followed for GERD have a lower quality of life scores for all dimensions of the RQS ${ }^{\circledR}$. Mungan reported also that this QoL score of patients with GERD is significantly decreased compared to the general population in Turkey [16]. Indeed, the study already published in the United States by Revickiet showed that patients affected by GERD have a severe impairment of their quality of life than hypertensive or diabetic subjects (15). In our study, the impairment was statistically associated elderly $(p=0.01)$, female $\operatorname{sex}(p=0.03)$ and the frequency of symptoms $(p=0.001)$. Moreover, patients having a GERD requiring a daily and continuous administration of PPIs had a lower index of $\mathrm{RQS}^{\circledR}(p=0.001)$. These results are similar to the literature data. In Ben Hriza study, female patients also had significantly lower scores [13]. Firoozi demonstrated a significant correlation between symptom severity and 
quality of life [12].

Several limitations of the study deserve to be cited: the first limitation is the recruitment of patients from the university medical center, certainly receiving more symptomatic patients with severe impact on the quality of life. This could introduce selection bias. The second limitation resides in the fact that the recall periods were long, and symptoms are assessed only by the patients. Also, the QOL questionnaire was self-reported. Nevertheless, it was administrated orally to minimize the effect of illiteracy.

\section{Conclusion}

The impairment of the QoL was moderated to severe $\left(\mathrm{RQS}^{\circledR}<16\right)$ for $2 / 3$ of the patients. This impairment was associated with the elderly, female sex, frequency and in case of GERD requiring continuous administration of PPIs. It is now admitted that the consideration of the quality of life is particularly important in the GERD, allowing the analysis of its impact on daily life and the effectiveness of the treatments introduced.

\section{Conflicts of Interest}

The authors declare no conflicts of interest regarding the publication of this paper.

\section{References}

[1] Sontag, S.J. (1993) Rolling Review: Gastro-Oesophageal Reflux Disease. Alimentary Pharmacology and Therapeutics, 7, 293-312. https://doi.org/10.1111/j.1365-2036.1993.tb00101.x

[2] Galmiche, J.-P. and Des Varannes, S.B. (1994) Symptoms and Disease Severity in Gastro-Oesophageal Reflux Disease. Scandinavian Journal of Gastroenterology, 29, 62-68. https://doi.org/10.3109/00365529409105366

[3] Johnsson, F., Joelsson, B., Gudmundsson, K. and Greiff, L. (1987) Symptoms and Endoscopic Findings in the Diagnosis of Gastroesophageal Reflux Disease. Scandinavian Journal of Gastroenterology, 22, 714-718. https://doi.org/10.3109/00365528709011148

[4] Raymond, J.M., et al. (1999) Assessment of Quality of Life of Patients with Gastroesophageal Reflux. Elaboration and Validation of a Specific Questionnaire. Gastroenterologie Clinique Biologique, 23, 32-39.

[5] Amouretti, M., et al. (2005) Validation of the Short-Form REFLUX-QUAL ${ }^{\circledast}\left(\mathrm{RQS}^{\circledast}\right)$, a Gastro-Esophageal Reflux Disease (GERD) Specific Quality of Life Questionnaire. Gastroentérologie Clinique et Biologique, 29, 793-801. https://doi.org/10.1016/S0399-8320(05)86350-X

[6] Wiklund, I., et al. (1998) Quality of Life during Acute and Intermittent Treatment of Gastro-Oesophageal Reflux Disease with Omeprazole Compared with Ranitidine. Results from a Multicentre Clinical Trial. The European Study Group. Italian Journal of Gastroenterology and Hepatology, 30, 19-27.

[7] Kinoshita, Y., Adachi, K., Hongo, M. and Haruma, K. (2011) Systematic Review of the Epidemiology of Gastroesophageal Reflux Disease in Japan. Journal of Gastroenterology, 46, 1092-1103. https://doi.org/10.1007/s00535-011-0429-3 
[8] Wong, B.C.Y. and Kinoshita, Y. (2006) Systematic Review on Epidemiology of Gastroesophageal Reflux Disease in Asia. Clinical Gastroenterology and Hepatology, 4, 398-407. https://doi.org/10.1016/j.cgh.2005.10.011

[9] Bretagne, J.-F., Richard-Molard, B., Honnorat, C., Caekaert, A. and Barthélemy, P. (2006) Gastroesophageal Reflux in the French General Population: National Survey of 8000 Adults. La Presse Médicale, 35, 23-31. https://doi.org/10.1016/S0755-4982(06)74515-8

[10] Maleki, I., Masoudzadeh, A., Khalilian, A. and Daheshpour, E. (2013) Quality of Life in Patients with Gastroesophageal Reflux Disease in an Iranian Population. Gastroenterology Hepatology from Bed to Bench, 6, 96-100.

[11] Mahadeva, S., et al. (2005) Gastro-Oesophageal Reflux is More Prevalent in Western Dyspeptics: A Prospective Comparison of British and South-East Asian Patients with Dyspepsia. Alimentary Pharmacology and Therapeutics, 21, 1483-1490. https://doi.org/10.1111/j.1365-2036.2005.02455.x

[12] Saberi-Firoozi, M., Khademolhosseini, F., Yousefi, M., Mehrabani, D., Zare, N. and Heydari, S.T. (2007) Risk Factors of Gastroesophageal Reflux Disease in Shiraz, Southern Iran. World Journal of Gastroenterology, 13, 5486-5491.

[13] Hriz, F.B., et al. (2010) Impact du reflux gastro-œsophagien sur la qualité de vie des patients. À propos d'une série tunisienne de 78 patients, La Revue de Médecine Interne, 31, S170. https://doi.org/10.1016/j.revmed.2010.03.286

[14] Smout, A.J.P.M. (1997) Endoscopy-Negative Acid Reflux Disease. Alimentary Pharmacology and Therapeutics, 11, 81-85.

https://doi.org/10.1111/j.1365-2036.1997.tb00798.x

[15] Revicki, D.A., Wood, M., Maton, P.N. and Sorensen, S. (1998) The Impact of Gastroesophageal Reflux Disease on Health-Related Quality of Life. The American Journal of Medicine, 104, 252-258. https://doi.org/10.1016/S0002-9343(97)00354-9

[16] Mungan, Z. (2012) Prevalence and Demographic Determinants of Gastroesophageal Reflux Disease (GERD) in the Turkish General Population: A Population-Based Cross-Sectional Study. The Turkish Journal of Gastroenterology, 23, 323-332. https://doi.org/10.4318/tjg.2012.0352 


\section{Appendix: Questionnaires Used for the Study}

Questionnaire number:

Socio-demographic characteristics:

- Age:

- Gender: $\square$ Male $\square$ Female

- Origin: $\square$ Urban $\square$ Rural

- Level of education:

$\square$ Illiterate $\square$ primary school $\square$ secondary school $\square$ high School

- Profession:

- Nationality:

- Maritalstatus: $\square$ Single $\square$ Married $\square$ Divorced $\square$ Widowed Chronic smoking: $\square$ Yes $\square$ No Type of symptoms:

- Heartburn: $\square$ Yes $\square$ No

- Regurgitations: $\square$ Yes $\square$ No

- Others: $\square$ No if yes: specify

The onset of symptoms:

$\square \leq 12$ months $\square>12$ months/ $\leq 60$ months

$\square>60$ months/ $\leq 120$ months $\square>120$ months

The rhythm of symptoms: $\square$ Diurnal $\square$ Nocturnal $\square$ Mixte

The severity of symptoms: $\square$ Minimal $\square$ Moderate $\square$ Severe

Frequency of symptoms: $\square$ Daily $\square>3$ days/week

$\square>1$ days/week $\square<3$ days/month

Daily PPIs treatment: $\square$ yes $\square$ No

Upper endoscopy: No if Yes results:

24-hour $\mathrm{pH}$ monitoring: No if Yes results:

The Reflux-Qual short form questionnaire (RQS ${ }^{\circledR}$ )

1) During the past 4 weeks, have you been bothered by your digestive problem when gardening, doing odd jobs, or doing house works?

$4 \square$ Not at all $3 \square$ Slightly $2 \square$ Moderately $1 \square$ Quite a bite

$0 \square$ Extremely

2) During the past 4 weeks, have you been bothered by your digestive problem, have you done less than usual?

$0 \square$ Never $\quad 1 \square$ Rarely $\quad 2 \square$ Sometimes $\quad 3 \square$ Often $\quad 4 \square$ all the time

3) During the past 4 weeks, have you felt satisfied with our life in general even though you have a digestive problem?

$4 \square$ Not at all $3 \square$ Slightly $2 \square$ Moderately $1 \square$ Quite a bite

$0 \square$ Extremely

4) During the past 4 weeks, considering our digestive problem, have enjoyed food?

$0 \square$ Never $\quad 1 \square$ Rarely $\quad 2 \square$ Sometimes $\quad 3 \square$ Often $\quad 4 \square$ all the time

5) During the past 4 weeks, have you been worried because of your digestive problem? 
$0 \square$ Never $\quad 1 \square$ Rarely $\quad 2 \square$ Sometimes $\quad 3 \square$ Often $\quad 4 \square$ all the time

6) During the past 4 weeks, because of your digestive problems, have you been in a bad mood?

$0 \square$ Never $\quad 1 \square$ Rarely $\quad 2 \square$ Sometimes $\quad 3 \square$ Often $\quad 4 \square$ all the time

7) During the past 4 weeks, have your digestive problems kept you awake most of the night?

$0 \square$ Never $\quad 1 \square$ Rarely $\quad 2 \square$ Sometimes $\quad 3 \square$ Often $\quad 4 \square$ all the time

8) During the past 4 weeks, have you avoided eating large meals because you were afraid of having digestive problems?

$0 \square$ Never $\quad 1 \square$ Rarely $\quad 2 \square$ Sometimes $\quad 3 \square$ Often $\quad 4 \square$ all the time 